\title{
REFERENCES
}

Broda, E. E., Goodeve, C. F. and Lythgòe, R. J. (1940).-Jl. Physiol., Vol. XCVIII, p. 397.

Dartnale, H. J. A. and Goodeve, C. F. (1937).-Nature, Lond., Vol. CXXXIX, p. 409.

Granit, R. (1941).-Acta physiol. Scand., Vol. II, p. 334.

LUdVIGH, E. and MCCARTH Y, E. F. (1938).-Arch.Ophthal. Chicago, Vol. XX, p. 37. LYTHGOE, R. J. (1937).-Jl. Physiol., Vol. LXXXIX, p. 331.

(1938).-Proc. phys. Soc., Vol. L, p. 321.

- (1940).-Brit. Jl. Ophthal., Vol. XXIV, p. 21.

Lythgoe, R. J. and QuilliaM, J. P. (1938).-Ji. Physiol., Vol. XCIII, p. 24.

OGuCHI, Ch. (1924). - v. Graefes A rch. Ophthal., Vol. CXV, p. 234.

PITT, F. H. G. (1944).-Nature, Lond., Vol. CLIV, p. 466.

SACHS, M. (1891).-Quoted by Parsons, J. H. in "An Introduction to the Study of Colour Vision," p. 40. Cambridge University Press, 1915.

Troland, L. T. (1922).-Ji. Opt. Soc. Amer., Vol. VI, p. 3.

WALD, G. (1938).-Jl. gen. Physiol., Vol. XXI, p. 795.

WhitTAKER, E. T. and Robinson, G. (1924).- "The Calculus of Observations." London : Blackie.

WRight, W. D. (1946).- "Researches on Normal and Defective Colour Vision." London: Henry Kimpton.

\section{SCLERAL RESECTION IN THE TREATMENT OF RETINAL DETACHMENT \\ (A Preliminary Report)}

BY

\section{Seymour Philps}

LONDON

THE great majority of retinal detachments are cured by Gonin's operation of scleral diathermy over the site of the retinal tear, but there remains a percentage which is not cured by this means. This percentage varies from 20 to 30 , and the causes of failure are various. Apart from those patients in whom inter-current disease or other factors make operation impossible, the causes of failure of the diathermy may be :-

(1) Failure to see and therefore to seal off the retinal tear.

(2) Retraction of the vitreous and shrinkage of the retina, making it too small to " fit " the eye, so that even after a successful diathermy operation the retina breaks away again.

Failure to see the Retinal Hole. If the media are transparent the whole of the retina can be examined ophthalmoscopically and a hole, if present, can be located. Lack of transparency of the media whether due to lens opacity, capsular remains or vitreous opacity may mean that the view of the retina is so poor that all efforts to locate a retinal tear are fruitless. 
A "blind" diathermy operation is rarely successful, and there is a definite limit to the area of scleral surface which can be diathermised without causing undue reaction in the eye, thrombosis of the vortex veins and a choroidal exudate and haemorrhage which makes the last condition of the patient worse than the first.

If one blind operation of limited extent over the supposed site of the hole is unsuccessful, it is better to carry out scleral resection than to repeat the diathermy.

Retraction of the Vitreous and Shrinkage of the Retina. Diathermy operations can only succeed if the retina can be got into contact with the choroid and remain there long enough for scar tissue to form. If, owing to the length of time the detachment has existed, or to other causes, the retina has contracted and shrunk, diathermy will be unsuccessful. Retraction of the vitreous in high myopia or aphakia will have the same effect.

The operation of scleral resection is designed to help those patients in whom the Gonin diathermy operation has failed, and who must otherwise become blind. It is not intended in any way to replace the diathermy operation, though it sometimes offers a better chance of cure where opacification of the media makes retinal examination impossible.

Where the retinal tear can be seen and treated the diathermy operation is the operation of absolute choice and should always be employed first. But where the lens opacities, capsular remains or vitreous opacities obscure the view scleral resection may be employed. Detachment of the retina after extracapsular extraction is an especial indication, as the capsule will almost certainly obscure the view of the peripheral retina and the site of the retinal tear cannot be located.

Indications. (1) Detachments with multiple rents and thin atrophic retina where diathermy has failed, or where the retina breaks away extensively after a successful diathermy operation.

(2) Detachment where no rent can be found because of obstruction to retinal examination.

(3) Long standing detachments where the retina has shrunk and will no longer fit the globe.

(4) Some detachments in very high myopia where the vitreous retraction and thin retina give, little chance of success with diathermy.

Rationale of the Operation. Scleral resection shortens the eye and this allows a shrunken retina once more to fit the globe; it also collapses the peripheral retina which contains the rents or degenerative patches which have caused the detachment. It may be employed round the whole $360^{\circ}$ of the globe though not more than $180^{\circ}$ should be attempted at a single operation, and the 
surgeon should aim to place the centre of the scleral arc he resects over the probable site of the retinal hole.

The operation takes time and patience but is not difficult, except perhaps when resecting those areas where repeated diathermy cauterisations have been employed. Certainly the operation is less difficult than those might think who have not employed it.

Anaesthesia.-Local instillation of cocaine 2 per cent. and adrenalin 1: 1000. Retrobulbar injection of novocaine 2 c.c.

Instruments.- Speculum (Lang's). Knife (Bard Parker No. 15 blade, ground down Graefe knife). Scissors (Fine, straight, pointed). Hooks (Double and single conjunctival squint hooks). Needle holders. Forceps (Conjunctival and fixation). Calipers. Measuring Rule. Ink Compass.

Sutures.-1. Traction-Maddox cataract needle 00 black silk. 2. ConjunctivalNo. 6 eye curved (two) No. 1 black silk. 3. Muscle-No. 6 eye curved (two) 00 white silk. 4. Scleral-8 double-armed Maddox cataract 00 white silk.

No special instruments are required for the operation, but the needles used must be good ones and should be tested carefully beforehand. A good Maddox cataract needle is required for scleral suture, though perhaps the Grieshaber corneal needle is best of all.

Preparation of Sutures for Scleral Resection.-The suture material used for the sclera should be 00 white silk and the method of preparing silk sutures in general and these in particular needs some explanation. The needles should be gold plated, as this prevents rust and gives a smoother surface which slides better through tough tissues. They are threaded by the theatre sister and each suture is tied to the needle with one half hitch. The sutures are then threaded into the non-fluffy side of a square of white lint, and when sufficient needles have been threaded for the operation the lint is folded into a packet and placed in the dressing drum along with towels, swabs, etc., to be autoclaved.

After sterilisation this suture packet is placed on the surgeon's tray and opened out ready for use. As each suture is required the surgeon picks it out of the lint with the needle holder and inserts it into the sclera.

The advantages of this method are as follows:-

(1) The sutures are handled by no-one. Their sterility is thus assured.

(2) They are dry and easy to use.

(3) They are under the surgeon's eve who picks them up as needed with no words spoken and no turning round to take them from another tray at his side or back; a great advantage when a number of sutures have to be inserted.

\section{TECHNIQUE}

Preparation of the Eye. The eyelids and facial nerve should be infiltrated with novocain and adrenalin to give a large palpebral fissure and the maximum space in which to work; after which a traction suture is inserted through episclera close to the limbus and the eye rotated to one side and fixed in that position. By this means it is possible to bring the area of resection into the centre of the operative field.

Exposure of the Operative Field. The conjunctiva is divided throughout the whole length of the planned resection and a rectus muscle detached from its insertion after being picked up with silk sutures. It will now be possible to take the eye over a little further by means of the traction suture and so gain more space for the resection. 
Marking out the Resection. The resected sclera should be about $4 \mathrm{~mm}$. wide and the. strip should extend round half the circumference of the globe, tapering a little at each end. The site of the resection must be over the peripheral retina between the equator and the ora serrata, and the anterior cut is made $10 \mathrm{~mm}$. from the limbus.

The lines of these incisions are marked out by a series of dots made with a sterile ink drawing compass, the sclera being well dried first to prevent the ink from running. When the incisions have been clearly marked out the resection may begin.

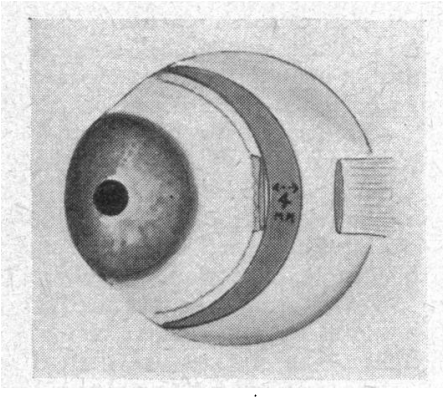

Fig. 1.

The size and shape of the scleral crescent to be resected showing the relation to the rectus muscle insertion.

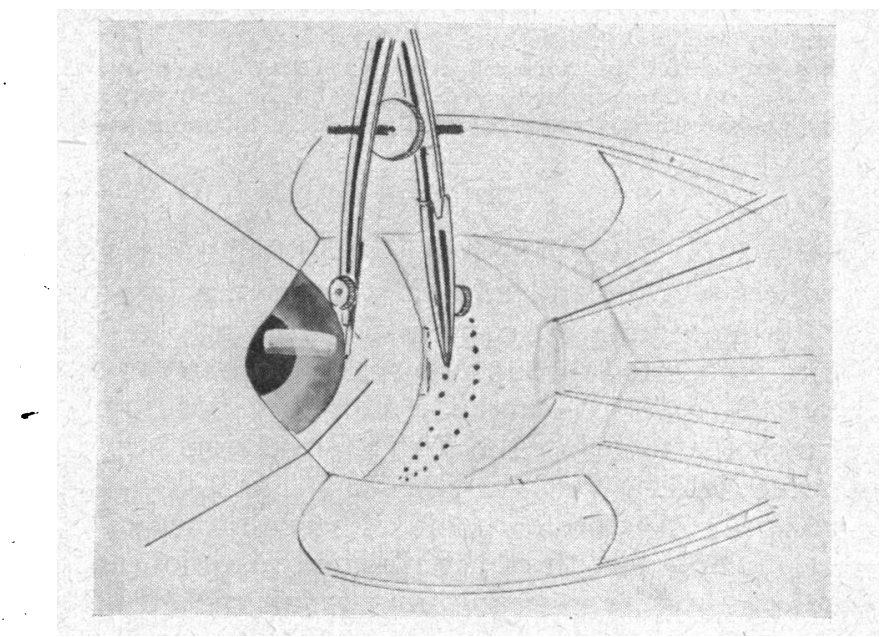

FIG. 2.

Marking out the area to be resected with an ink compass. The two lines of dots are at 10 and $14 \mathrm{~mm}$. from the limbus. 


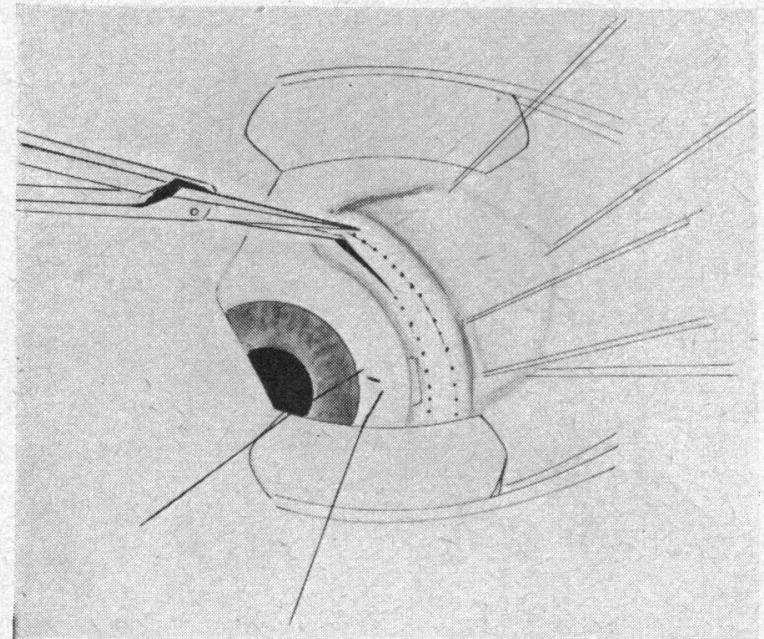

FIG. 3.

Method of starting the resection.-A knife cut has been made through the sclera and the incision is extended from that point along the posterior dotted line with fine straight scissors.

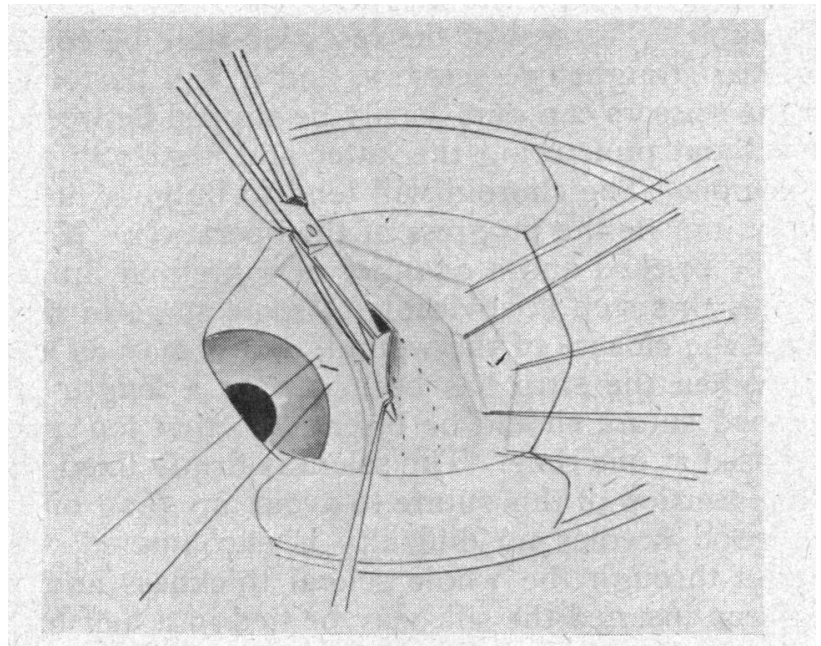

FIG. 4.

Continuation of the resection by means of scissors. The scleral arc is retracted with a hook. 


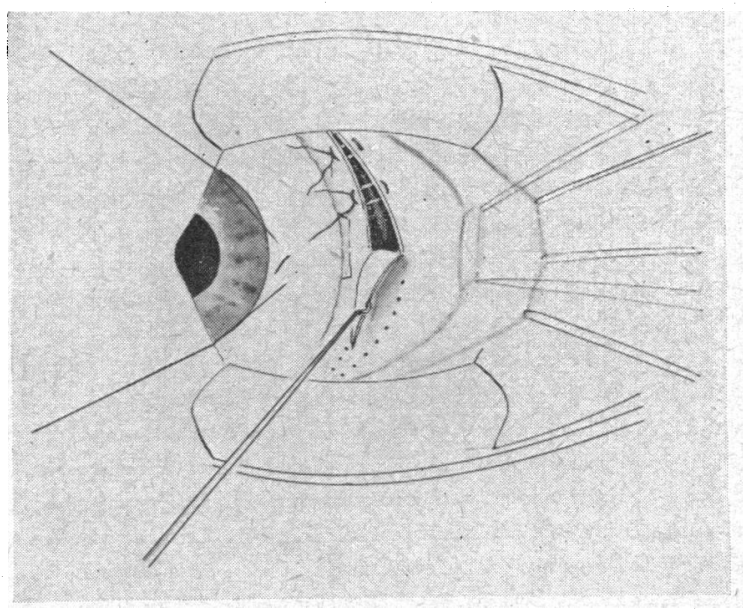

F!G. 5.

Method of inserting the sutures as the resection proceeds.

The Scleral Resection. The surgeon should be seated in such a position that the cutting instrument comes naturally to the right hand. Starting at one end of the scleral crescent the incision is begun with a knife-a Bard Parker is convenient (No. 15 blade)by making a cut through the sclera until the shining black choroid shows through. The rest of the resection may be continued with good pointed straight eye scissors, and it will be found that one blade of the scissors can quite easily be slipped between sclera and choroid without puncturing the latter and a strip of sclera raised in this fashion. The choroid will tend to bulge a little, but does not usually impede the progress of the operation. If it should do so it may be pricked and a quantity of subretinal fluid evacuated. In any case, this step is advisable at some stage in the operation to facilitate the closure of the wound, and it may as well be early as late. When the strip has been cut for a length of $5 \mathrm{~mm}$. a double-armed suture should be inserted so that too much choroid is not exposed at one time. The sclera is firmly fixed with forceps before the insertion of this suture to avoid any drag on the tissues, but with good needles no difficulty is encountered. The suture should pass through the whole scleral thickness and when each limb has been inserted the silk may be tied in a half hitch and the wound edges drawn together. By continuing this process of cutting and suturing the whole $180^{\circ}$, or whatever resection is planned, may be accomplished without great difficulty, except sometimes in an area where repeated diathermy operations have 
been performed. In such places the choroid may be adherent and more difficult to separate from sclera, but it can always be achieved with care and patience. In other parts the scissors slip easily along the suprachoroidal lymph space.

When all the sutures have been inserted the surgeon goes back to the beginning of the resection and, tightening each suture a little, completes the knot and cuts off the ends. With replacement of the rectus muscle and suture of the conjunctiva the operation is completed.

Atropine is instilled and both eyes are bandaged.

Post-Operative Treatment. This is much as for retinal detachment. The patient should be semi-prone on the back in a position of comfort, and the first dressing can be undertaken after two clear days have elapsed from the time of the operation. Binocular bandages are retained for a fortnight and the patient is got up three weeks after the operation.

Post-Operative Course. In a successful case the detachment is much improved when first examined at the end of one week, but there will usually remain some small amount of detachment for some weeks which slowly disappears. The reaction from this operation is much less than might be supposed from its extensive nature, and usually is no more than might be expected after a diathermy operation.

\section{Case Reports}

(1) J.T., aged 59 years, London labourer. Presented himself at the Moorfields, Westminster, and Central Eye Hospital having lost the sight of the right eye, which was his only useful eye, following an accident two days previously.

Past History.- Ten years before, he had developed a cataract in the left eye and since that time had depended on the right eye, which was good. Two days before admission, while demolishing a building, a piece of concrete struck him in the right eye, the sight of which deteriorated over the next two days.

Examination.-The patient was a big heavy man, six foot tall and sixteen stone in weight. Right eye, vision $6 / 36$, vitreous haemorrhage obscured many fundus details but there was a detachment of the outer half of the retina, no hole being found owing to the turbid vitreous humour. L.E. Vision=Perception of light. There was a mature cataract, but light projection was accurate and quick.

Treatment. - The patient was put to bed in binocular bandages but in spite of this the right retinal detachment increased and operation had to be undertaken under most unfavourable circumstances over the probable site of the retinal hole.

After two diathermy operations the right retina was even more detached than before and lens and vitreous opacities prevented any adequate fundus view. It was therefore decided to remove the left cataract, which was accordingly done by the intracapsular method on April 12, 1947. In spite of a very good operative result, the retina was found to be detached centrally, below, and to the outer sidevery atrophic and the best vision less than $6 / 60$. By this time the right retinal detachment was total and the media opaque, and the only hope of preserving any useful vision lay in improving the left eye. In this eye the retina on the temporal side was all so thin and lacelike that it was difficult to say which areas contained holes and which were merely atrophic. A diathermy operation all down the temporal half of the globe was unsuccessful, and the man finally left hospital with so little vision that he could not see his way about; but on reading a report in 
the American ophthalmic literature of the scleral resection operation ${ }^{1}$, it was decided to re-admit him and try to improve the left eye by this means. At this time $3 / 4$ of the left retina was detached, the only portion remaining attached was between 10 and 12 o'clock. It was still thought most probable that the original tears causing this detachment were situated above and temporally and so a scleral resection of the outer half of the globe from XII to VI was planned as a firststage. This was performed on January 10,1948, after the method described, and the patient was discharged on February 15, 1948, with the retina in place.

The patient was last seen in July, 1948, with the retina still in place. Although, owing to the size of the detachment which had been present, the vision was not more than 5/60 the field was quite good and the patient could see his way around by himself. The line of the scleral resection can be seen quite clearly all down the outer half of the fundus on ophthalmoscopy.

(2) E.B., aged 10 years, London schoolgirl. Was brought by her mother to St. Bartholomew's Hospital on March 20, 1947. The child's left eye had been found to be defective and in spite of the fact that the mother had been advised that this eye was lazy and had been defective since birth, she (the mother) decided to seek other advice as, having herself suffered from retinal detachment, she thought it possible her daughter might suffer from it also.

Past History.-The girl had had a blow in the left eye with a stone three years previously. She had no idea when the left vision began to fail as the defect was discovered during a routine school examination.

Examination.-Right Eye 6/6 unaided-Normal. Left Eye less than 6/60Counts fingers at one foot.

The left retina was extensively detached, the whole temporal half of the retina including the macula being separated. A disinsertion extended from 11.30 o'clock right round the temporal periphery to 5.30 , the area of greatest disinsertion being in the 2.30 meridian.

On March 25, 1947, a diathermy operation was performed and was successful in replacing the retina. The girl left hospital on April 15 with a full field and vision of $4 / 60$. The retina stayed in place until January, 1948, when it suddenly broke away from the scar and once more a long ragged retinal tear appeared from 2 to 5 o'clock, the whole retina being now detached. It was felt that a further diathermy was unlikely to be successful as the retina had retracted so far away from the choroid, and in order to prevent this eye becoming quite blind and undergoing the secondary changes and complications usual in an uncured detachment, a scleral resection was undertaken in February, 1948, to bring the retina nearer to its bed and enable it to become attached again. This resection was from 12 to 5.30 o'clock and the area resected was that strip between 12 and 15-16 millimetres from the limbus. Following this the retina settled in place and has remained so since that time. The vision is poor as the macula was detached, but the media are clear, the eye quiet and cosmetically normal.

This preliminary report is intended to show that the operation has possibilities and is worth serious consideration in those patients where diathermy has failed and who will otherwise go blind.

\section{REFERENCE}

1. VAIL.-Scleral resection operation. Amer. Jl. Ophthal., XXIX. 745-800, 1946. 